\title{
Diagnostic challenges leading to underdiagnosis of dissociative disorders
}

This article was published in the following Dove Press journal:

Neuropsychiatric Disease and Treatment

8 February 2017

Number of times this article has been viewed

\author{
Muhammad Aadil' \\ Maria Shoaib ${ }^{2}$ \\ 'Department of Psychiatry, Rush \\ University Medical Center, Chicago, IL, \\ USA; ${ }^{2}$ Department of medicine, Dow \\ Medical College, Karachi, Pakistan
}

\section{Dear editor}

We read the article "Is the Dissociative Experiences Scale able to identify detachment and compartmentalization symptoms? Factor structure of the Dissociative Experiences Scale in a large sample of psychiatric and nonpsychiatric subjects" by Mazzotti et al with great interest and would like to add our views in its support. ${ }^{1}$

Diagnostic and Statistical Manual of Mental Disorders (DSM-5) states that dissociative disorders (DDs) are characterized by a disruption of and/or discontinuity in the normal integration of consciousness, memory, identity, emotion, perception, body representation, motor control, and behavior. ${ }^{2}$ It further states that dissociative symptoms can potentially disrupt every area of psychological functioning. ${ }^{2}$

DD is believed to be strongly associated with borderline personality disorder presenting with symptoms of dissociation and some overlapping features of posttraumatic stress disorder (various researchers are proving increasing number of patients who develop features of DD after encountering trauma), substance abuse, sexual abuse, depression, and somatoform conditions, which make the establishment of diagnosis very difficult even for a seasoned clinician. ${ }^{3}$

As stated in DSM-5, the 12-month prevalence of dissociative identity disorder among adults in a small US community study was $1.5 \%{ }^{2}$ The prevalence across genders in that study was $1.6 \%$ for males and $1.4 \%$ for females. ${ }^{2}$ Two studies in North America demonstrated that $13.0 \%-20.7 \%$ of psychiatric inpatients had a DD. ${ }^{3}$ Studies on DDs in Istanbul, Turkey, yielded the prevalence slightly above $10 \%$ among psychiatric inpatients and outpatients. ${ }^{3}$ The choice of diagnostic instrument and cultural differences in interpretation of symptoms seem to be major explanations for differences in the prevalence of DDs and dissociative identity disorder (DID). ${ }^{3}$

Research on DD is constrained by various obstacles atypical for those of other psychiatric disorders. ${ }^{4}$ The impediments cover five areas: diagnostic concerns, cultural issues, posttraumatic avoidance, cost-benefit issues, and conceptual challenges. ${ }^{4}$

This study provides hope to overcome these limitation barriers. The biggest limitation to this study is the lack of test-retest stability, which was not investigated and no other dissociative experience questionnaire was used. Despite this, the result shows Dissociative Experience Scale could be the most valid tool for evaluating the frequency of various types of dissociative experience. It provides physician with the additional information about dissociative experience as well as important treatment indicator.
Correspondence: Muhammad Aadi Department of Psychiatry, Rush

University Medical Center, II 37 S Taylor

Oak Park, Chicago, IL 60304, USA

Tel +l 2247047195

Email muhammad.aadil9@gmail.com 


\section{Disclosure}

The authors report no conflicts of interest in this communication.

\section{References}

1. Mazzotti E, Farina B, Imperatori C, et al. Is the Dissociative Experiences Scale able to identify detachment and compartmentalization symptoms? Factor structure of the Dissociative Experiences Scale in a large sample of psychiatric and nonpsychiatric subjects. Neuropsychiatr Dis Treat. 2016;12:1295-1302.
2. American Psychiatric Association. Diagnostic and Statistical Manual of Mental Disorders. 5th ed. Washington, D.C: American Psychiatric Association; 2013.

3. Sar V. Epidemiology of dissociative disorders: an overview. Epidemiol Res Int. 2011;2011:404538.

4. Dorahy MJ, Brand BL, Şar V, et al. Dissociative identity disorder: an empirical overview. Aust N Z J Psychiatry. 2014;2016/12;48(5):402-417. 


\section{Authors' reply \\ Benedetto Farina \\ Claudio Imperatori \\ Department of Human Sciences, European University of Rome, Rome, Italy}

Correspondence: Claudio Imperatori

Università Europea di Roma, Via degli Aldobrandeschi 190, Rome

00163 , Italy

Email imperatori.c@libero.it

\section{Dear editor}

We have carefully read the letter of Aadil and Shoaib and wish to thank the authors for the valuable feedback. They highlighted the importance of clinicians correctly recognizing and evaluating dissociative experiences. We totally agree with them and would like to extend their comments on the diagnostic challenges of dissociation.

\section{What if dissociation were a psychopathological dimension related to trauma?}

Although dissociation has been extensively explored in the last century, both in theoretical debates and in empirical research, it is far from having a unique definition, and its psychopathology presents controversial issues. One confounding factor could be the multiple meanings of the term "dissociation". It is used to define at least three different, albeit related, concepts, namely, a diagnostic category (ie, dissociative disorders), a varying group of psychopathological phenomena and symptoms (eg, depersonalization or amnesia), and pathogenic processes caused by traumatic experiences that interfere with the integration of high-order mental functions. ${ }^{1}$

Not by chance, as mentioned by Aadil and Shoaib, in the Diagnostic and Statistical Manual of Mental Disorders (DSM-5), dissociation is defined as the loss of high-order integrative capacities of the human mind, specifically the "disruption of and/or discontinuity in the normal integration" of different mental functions, such as "consciousness, memory, identity, emotion, perception, body representation, motor control, and behavior". ${ }^{2}$

This definition leads to the association of the word "dissociative" with a wide range of different psychopathological phenomena, from alterations of self-consciousness, such as detachment symptoms (eg, derealization/depersonalization), to fragmentation of self-experiences, such as compartmentalization symptoms (eg, amnesia, motor control), and even to a sudden loss of control on emotions and behavior. The latter psychopathological manifestations, although not considered typical dissociation, are very common in people suffering from trauma-related disorders, such as borderline personality disorder, post-traumatic stress disorder (PTSD), or complex PTSD, and are supposed to be generated by disintegrative processes. ${ }^{3,4}$

The complexity and variety of dissociative manifestations, as indicated in the DSM-5 definition, are related to the variety of functions impaired by trauma. For all these reasons, we are contemplating on the opportunity to reinsert in psychopathology, the term traumatic "disintegration", anticipated by Janet ${ }^{5}$ at the beginning of the 20th century (désagrégation in French, 1901), and as lately proposed by several scholars. ${ }^{1,3}$

In any case, as Aadil and Shoaib stated, Dissociative Experiences Scale (DES) is a valid tool to assess the frequency of various types of dissociative experiences (detachment, compartmentalization), but not for all dissociative symptoms. Somatoform dissociation, loss of control on emotions and behavior, and other atypical dissociative phenomena ${ }^{6}$ may require additional diagnostic instruments. Otherwise, some clinicians could run the risk of neglecting the traumatic-dissociative origin of these psychopathological manifestations.

In their letter, Aadil and Shoaib also underlined the high prevalence of dissociative symptoms among psychiatric patients. Comorbidities with dissociative phenomena seem to characterize patient subgroups with histories of traumatic development and low response to treatment. An increasing amount of empirical controlled data supporting this hypothesis are available for schizophrenia, several personality disorders, mood disorders, somatoform disorders, obsessive-compulsive disorder, substance use disorders, eating disorders, and anxiety disorders. ${ }^{1}$ The evidence has led some scholars to hypothesize that trauma-based dissociation should also be considered a psychopathological dimension. This dissociative or traumatic-dissociative dimension, when associated with other disorders, has been hypothesized and partially demonstrated to worsen prognosis and lead to specific therapeutic difficulties. ${ }^{1}$ In our opinion, these are new challenges in the diagnosis of traumatic dissociation.

\section{Disclosure}

The authors report no conflicts of interest in this communication.

\section{References}

1. Farina B, Liotti G. Does a dissociative psychopathological dimension exist? A review on dissociative processes and symptoms in developmental trauma spectrum disorders. Clin Neuropsy. 2013;10(1):11-18. 
2. American Psychiatric Association. Diagnostic and Statistical Manual of Mental Disorders. 5th ed. Arlington, TX: American Psychiatric Publishing; 2013.

3. Meares R. A Dissociation Model of Borderline Personality Disorder. New York, NY: Norton; 2012.

4. Sar V. Developmental trauma, complex PTSD, and the current proposal of DSM-5. Eur J Psychotraumatol. 2011;2;5622.
5. Janet P. The Mental State of Hystericals. New York, NY/London, UK: Putnam; 1901.

6. Van der Hart O, Nijenhuis E, Steele K. The Haunted Self: Structural Dissociation and the Treatment of Chronic Traumatization. New York, NY/London, UK: Norton; 2006.

Dove Medical Press encourages responsible, free and frank academic debate. The content of the Neuropsychiatric Disease and Treatment 'letters to the editor' section does not necessarily represent the views of Dove Medical Press, its officers, agents, employees, related entities or the Neuropsychiatric Disease and Treatment editors. While all reasonable steps have been taken to confirm the content of each letter, Dove Medical Press accepts no liability in respect of the content of any letter, nor is it responsible for the content and accuracy of any letter to the editor.

\section{Publish your work in this journal}

Neuropsychiatric Disease and Treatment is an international, peerreviewed journal of clinical therapeutics and pharmacology focusing on concise rapid reporting of clinical or pre-clinical studies on a range of neuropsychiatric and neurological disorders. This journal is indexed on PubMed Central, the 'PsycINFO' database and CAS, and is the official journal of The International Neuropsychiatric Association (INA). The manuscript management system is completely online and includes a very quick and fair peer-review system, which is all easy to use. Visit http://www.dovepress.com/testimonials.php to read real quotes from published authors.

\footnotetext{
Submit your manuscript here: http://www.dovepress.com/neuropsychiatric-disease-and-treatment-journal
} 